\title{
Within-host evolution of Brucella canis during a canine brucellosis outbreak in a kennel
}

\author{
Miklós Gyuranecz ${ }^{1 \dagger}$, Brandy D Rannals ${ }^{2+}$, Christina A Allen ${ }^{2}$, Szilárd Jánosi ${ }^{3}$, Paul S Keim ${ }^{2}$ and Jeffrey T Foster ${ }^{2 *}$
}

\begin{abstract}
Background: Little is currently known about Brucella evolution within the host during infection. The current study is the first to employ fine-scale genotyping on an isolate collection derived from a Brucella canis outbreak. Eight isolates of $B$. canis, cultured from different tissues of three dogs (female, stud dog, puppy of another female) from a single kennel over three months were genetically characterized with a 15-marker multi-locus, variable-number tandem repeat (VNTR) analysis (MLVA) to assess the genetic relatedness of isolates and potential rapid mutational changes.

Results: MLVA discriminated among the otherwise indistinguishable isolates from different animals and from isolates collected at different time points within each host, with different VNTR alleles being detected at multiple dates and tissue sites. We suspect that all isolates cultured from the female, puppy, and stud dogs originated from the same strain, with subsequent rapid in vivo mutations. However, high mutation rates and apparent in several of the loci prevented making definitive epidemiological relationships among isolates.

Conclusions: This investigation highlights the rapid in vivo genetic mutations of several VNTRs of $B$. canis over a short time period in the host and the emergence of alternate alleles. However, this work also suggests the challenges of using highly mutable VNTRs to infer epidemiological relationships of strains within a short duration outbreak.
\end{abstract}

Keywords: Brucella canis, Brucellosis, Evolution, MLVA, VNTR

\section{Background}

Brucella canis, the etiologic agent of canine brucellosis, can lead to severe economic loss in infected kennels. Canine brucellosis is a contagious disease transmitted via contaminated reproductive, oronasal, or conjunctival fluids [1]. The bacteria are particularly associated with reproductive tissue, causing abortion in females and epididymitis and prostatitis in males [2]. Brucella canis affects human beings, but few cases are reported in humans $[1,3]$ or other animals, suggesting either hostpreference for dogs or limited opportunities for transmission to other species.

Several multi-locus, variable-number tandem repeat (VNTR) analysis (MLVA) systems have been developed and described for Brucella species [4-7]. MLVA is a

\footnotetext{
* Correspondence: Jeff.Foster@nau.edu

${ }^{\dagger}$ Equal contributors

${ }^{2}$ Center for Microbial Genetics \& Genomics, Northern Arizona University, 1298

S. Knoles Drive, Flagstaff, AZ 86011-4073, USA

Full list of author information is available at the end of the article
}

rapid, reproducible molecular typing system providing high discriminatory power among closely related strains $[8,9]$. These characteristics make MLVA a potentially powerful tool for epidemiological (e.g. to follow local epidemics) and forensic investigations of events involving Brucella species [10-14] and many other bacterial agents. This molecular approach specifically allows for fine-scale detail on likely source populations of new brucellosis cases in human cases [14-16] and tracking outbreaks in wildlife and livestock $[7,17]$.

The first known outbreak of $B$. canis infection in Hungary was described in 2009 [18]. The affected kennel population consisted of 31 dogs of various ages. The disease was most likely introduced to the kennel by a pregnant female whose abortion was the first obvious reproductive disorder in October 2008 [18]. Sporadic reproductive clinical symptoms were detected by the breeder during the eight months preceding the first laboratory examination.

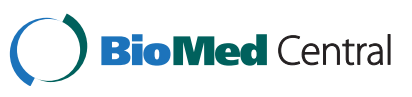

(c) 2013 Gyuranecz et al.; licensee BioMed Central Ltd. This is an Open Access article distributed under the terms of the Creative Commons Attribution License (http://creativecommons.org/licenses/by/2.0), which permits unrestricted use, distribution, and reproduction in any medium, provided the original work is properly cited. 
The aim of this study was to genetically characterize the eight strains of $B$. canis isolated from three dogs in a kennel during three months of the outbreak. Our goal was to use MLVA to assess the level of within-host genetic variation at different dates and sampling sites on the dogs for a better understanding of rapid Brucella evolution and its use for epidemiology.

\section{Methods}

Samples of blood, vagina and throat swabs and lymph nodes (mesenteric and sublingual lymph nodes) were obtained from every resident dog at 1-month intervals in June, July and August 2009. All experiments were performed in accordance with all applicable institutional and national guidelines and regulations and with the consent of the dog owner. The samples were collected from tissues typical for clinical brucellosis investigations and submitted for bacteriological examination as described previously [18]. Eight B. canis isolates (Bc 1-8) were recovered from three animals on selective Brucella agar plates (Oxoid Ltd., Cambridge, United Kingdom) (Table 1). Primary isolates were subcultered on trypticase soy agar plates (Difco, BD Diagnostic Systems, Sparks, MD) three times to reveal pure culture before DNA extraction (QIAamp DNA Mini Kit, Qiagen Inc., Valencia, CA).

Species identity for all isolates was confirmed by realtime PCR by a B. canis-specific assay [19]. The eight isolates were screened with a 15-marker MLVA system as previously described [5], with modifications. We redesigned the three largest VNTR primer sets (VNTRs 2, $29,33)$ to create smaller amplicons to reduce this potential source of allelic variation (Table 2). Larger amplicons generally exhibit greater variation in sizing due to loss of linearity for ladder fragment standards above 500 bp. We ran these new primers in $10 \mu \mathrm{l}$ reactions in singleplex under the following conditions: $1 \times$ PCR buffer, $2 \mathrm{mM} \mathrm{MgCl}_{2}, 0.2 \mathrm{mM}$ dNTPs, 0.04 U platinum Taq
DNA polymerase (Invitrogen, Carlsbad, CA), $0.10 \mu \mathrm{M}$ forward primer and $0.08 \mu \mathrm{M}$ reverse primer. Thermocycling parameters were an initial denaturation at $94^{\circ} \mathrm{C}$ for $5 \mathrm{~min}$, followed by $94^{\circ} \mathrm{C}$ for $45 \mathrm{~s}, 65^{\circ} \mathrm{C}$ for $45 \mathrm{~s}$ and $72^{\circ} \mathrm{C}$ for $45 \mathrm{~s}$ for 35 cycles, and a final annealing step at $72^{\circ} \mathrm{C}$ for $5 \mathrm{~min}$.

VNTR PCR amplicons were discriminated through electrophoretic analysis with an ABI PRISM 3130xl automated fluorescent capillary DNA sequencer (Applied Biosystems Inc., Foster City, CA). All samples were run in triplicate with three different PCR steps each as well as on different fragment analysis runs to examine the reproducibility of the analyses. Each run contained validated B. melitensis and B. suis DNA standards as positive controls. Fragment analysis was performed with GeneMapper software (Applied Biosystems). Fragment sizing was accomplished by comparison to a 1200 base LIZ-labelled size standard (Applied Biosystems). Customized bins for allele calls in GeneMapper allowed automated scoring of the VNTR alleles. When isolates had more than one amplification peak (i.e. multiple alleles at a locus), we chose the highest peak as the main allele but also recorded alternate alleles. Phylogenetic relationships derived from complete MLVA genotypes were determined using maximum parsimony algorithm in PAUP 4.0 Beta 10 (Sinauer Associates Inc., Sunderland, MA).

\section{Results}

Ten of the 15 MLVA loci did not mutate in any of the strains (Table 1). VNTR 3 had the same allele for 7 isolates and had a null allele for 1 isolate so was considered monomorphic in our analyses. For polymorphic loci, VNTRs 1 and 30 had single repeat insertions in isolate Bc 6. Both VNTR 2 and 33 were highly variable among the eight isolates and demonstrated multiple repeat changes. Alternate alleles occurred in three of these loci, VNTRs 1,2 , and 33. In 8 of 10 instances the alternate allele was present as the primary allele in at least one other

Table 1 Summary of host, isolation date, source and primary and alternate VNTR alleles of the studied strains

\begin{tabular}{|c|c|c|c|c|c|c|c|c|c|c|c|c|c|c|c|c|c|c|c|c|c|}
\hline \multirow[b]{2}{*}{$\begin{array}{l}\text { Isolate } \\
\text { ID }\end{array}$} & \multirow[b]{2}{*}{ Host } & \multirow[b]{2}{*}{$\begin{array}{l}\text { Isolation } \\
\text { date }\end{array}$} & \multirow[b]{2}{*}{$\begin{array}{l}\text { Isolation } \\
\text { source }\end{array}$} & \multicolumn{7}{|c|}{ Polymorphic VNTR } & \multicolumn{11}{|c|}{ Monomorphic VNTR } \\
\hline & & & & 1 & 1 alt & 2 & 2 alt & 30 & 33 & 33 alt & 3 & 7 & 14 & 16 & 20 & 21 & 25 & 27 & 28 & 29 & 31 \\
\hline $\mathrm{BC} 1$ & \multirow{3}{*}{$\begin{array}{l}\text { female, } \\
\text { abortion } \\
\text { in June }\end{array}$} & June & foetus & 234 & & 214 & & 568 & 295 & 303 & 417 & 306 & 121 & 233 & 439 & 100 & 490 & 413 & 198 & 260 & 507 \\
\hline BC 2 & & July & blood & 234 & 242 & 206 & 214 & 568 & 303 & & - & 306 & 121 & 233 & 439 & 100 & 490 & 413 & 198 & 260 & 507 \\
\hline $\mathrm{BC} 3$ & & July & vagina & 234 & & 206 & & 568 & 263 & & 417 & 306 & 121 & 233 & 439 & 100 & 490 & 413 & 198 & 260 & 507 \\
\hline Bc 4 & \multirow{2}{*}{$\begin{array}{l}\text { stud dog, } \\
\text { without clinical } \\
\text { symptoms }\end{array}$} & July & blood & 234 & & 214 & & 568 & 303 & 311 & 417 & 306 & 122 & 233 & 439 & 100 & 490 & 413 & 198 & 260 & 507 \\
\hline $\mathrm{BC} 5$ & & August & $\begin{array}{l}\text { lymph } \\
\text { node }\end{array}$ & 234 & & 231 & & 568 & 295 & & 417 & 306 & 121 & 233 & 439 & 100 & 490 & 413 & 198 & 260 & 507 \\
\hline $\mathrm{BC} 6$ & \multirow{3}{*}{$\begin{array}{c}\text { female puppy, } \\
\text { born with } \\
\text { infection in } \\
\text { March }\end{array}$} & July & blood & 242 & 250 & 150 & 214 & 574 & 255 & 263 & 417 & 306 & 121 & 233 & 439 & 100 & 490 & 413 & 198 & 260 & 507 \\
\hline $\mathrm{BC} 7$ & & August & blood & 234 & & 214 & & 568 & 255 & 263 & 417 & 306 & 121 & 233 & 439 & 100 & 490 & 413 & 198 & 260 & 507 \\
\hline BC 8 & & August & $\begin{array}{l}\text { lymph } \\
\text { node }\end{array}$ & 234 & 242 & 214 & & 568 & 255 & 263 & 417 & 306 & 121 & 233 & 439 & 100 & 490 & 413 & 198 & 260 & 507 \\
\hline
\end{tabular}


Table 2 Newly designed primers for three largest amplicons from Huynh et al. 2008

\begin{tabular}{llll}
\hline Locus & Amplicon size & F primer $\left(\mathbf{5}^{\prime} \mathbf{-} \mathbf{3}^{\prime}\right)$ & $\mathbf{R}$ primer $\left(\mathbf{5}^{\prime} \mathbf{-} \mathbf{3}^{\prime}\right)$ \\
\hline VNTR 2 & $178 \mathrm{bp}$ & cgctctcctcgcccgcttcttctt & tgttttggttgcgcatggccg \\
VNTR 29 & $150 \mathrm{bp}$ & gtttgtcgtcgcgggagagattagggg & cggcaggcgcttgaggatgagg \\
VNTR 33 & $213 \mathrm{bp}$ & cggataggcgcggcgtgagtaagg & acaacatggcgcgtgaaaggccc \\
\hline
\end{tabular}

isolate. Phylogenetic analysis of the eight samples placed the isolates onto three branches with genetic differences among the strains within each branch (Figure 1a). Six of the eight isolates had unique genotypes. Strains from the same dog but taken at different dates or collection sources occurred on different branches. For instance, strain Bc 1 appears more closely related to strains Bc 4, 5, 6, 7 and 8 than it does to Bc 2 and 3, although Bc 1, 2, and 3 all came from the same female dog. Isolates Bc 4 and 5 came from the same stud dog a month apart but were more closely related to other isolates on the tree from different dogs. Isolate Bc 6 from the puppy (from another female than the one described here) was genetically quite distinct from any other isolates and had different alleles at VNTRs 1 and 30. Interestingly, Bc 6 was collected a month earlier than two additional isolates from this $\operatorname{dog}$ (Bc $7 \& 8$ ).

Including alternate alleles in the analysis by using clouds instead of circles and lines allows illustration of the high degree of overlap among primary and alternate alleles (Figure 1b). For VNTR 1, the primary allele for

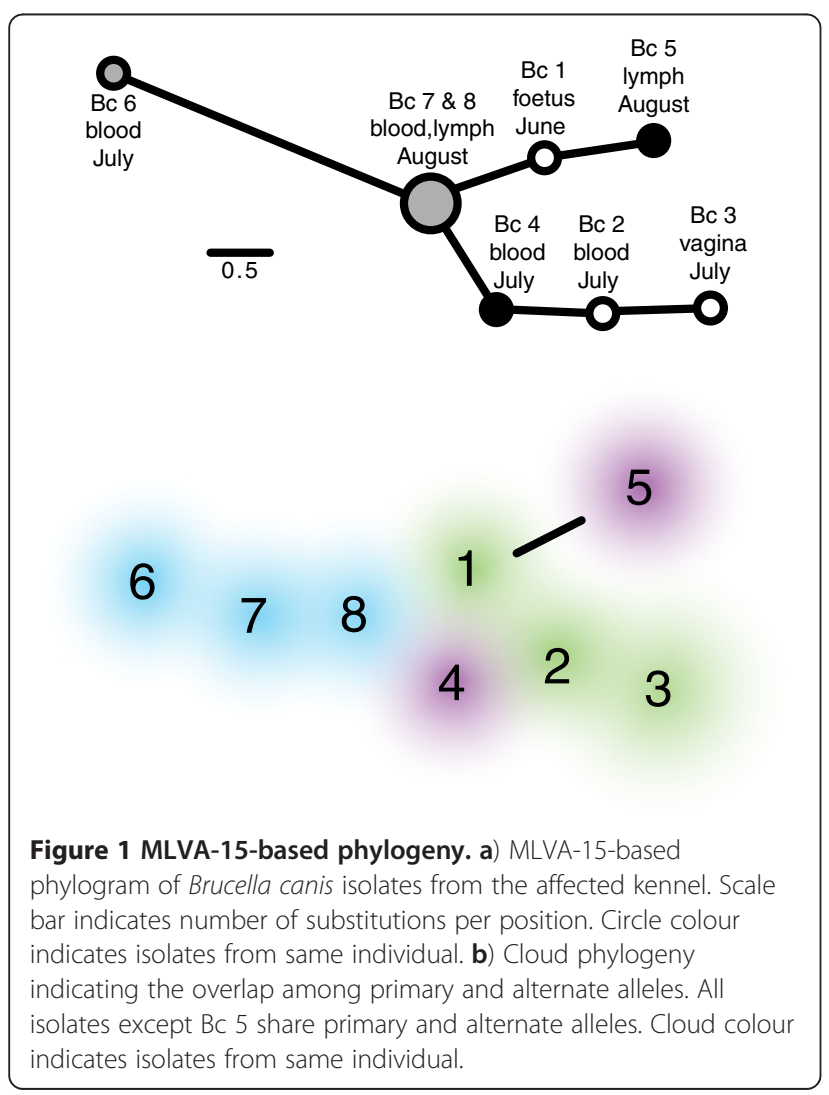

Bc 6 was shared with Bc 2 \& 8. VNTR 2 had the primary allele for Bc 1, 4, 7, \& 8 shared with Bc 2 \& 6. Finally, VNTR 33 had Bc $2 \& 4$ share an allele with Bc 1 and the primary allele in Bc 3 was shared with Bc 6, 7 \& 8. Thus, there was considerable overlap among genotypes when primary and alternate alleles were evaluated.

\section{Discussion}

MLVA provided discrimination among the otherwise indistinguishable isolates from different animals and from within each host, with VNTR mutations being detected at multiple dates and tissue sites. It is strongly suspected that the strains isolated from the dogs originated from the same recent introduction to the kennel, with subsequent rapid in vivo mutations. Strain Bc 1 was isolated from the foetus of the female in June. This isolate is distantly related in the tree to $\mathrm{Bc} 2$ \& 3 originating from the blood and vagina, respectively, from that female in July. Since these genotypes are closely related to the rest of the isolates and these isolates came from a foetus, the female parent was almost certainly infected as well. Additional in vivo evolution route also occurred in the stud dog with VNTR mutations between the collections of the July (Bc 4) and August (Bc 5) isolates. Similar in vivo evolution was observed in the case of the isolates (Bc 6-8) of the female puppy as well. These results are consistent with rapid within-host evolution of Burkholderia pseudomallei in acute infections in humans [9], demonstrating that VNTR changes can happen within weeks, as well as data from Yersinia pestis in fleas their prairie dog hosts that are consistent with within host evolution [20]. High mutation rates are inferred for several of the loci we used in our MLVA. Although Huynh et al. [5] found that average allelic diversity for $B$. suis (of which $B$. canis is a distinct lineage within it) was a moderate 0.49 , allelic diversity in VNTRs 2, 3, 1, 33, 30 was quite high at $0.77-0.88$, with the number of alleles per locus ranging from 6-13, indicating that these loci account for much of the diversity seen over short time periods. We must note that although minimal generations occurred during culturing during the short incubation period, we cannot rule out some mutations occurring in vitro. Direct MLVA testing on samples prior to culturing is recommended in future studies to rule out this possibility, although the number of generations within the dogs would be expected to be much higher than what is typical under standard culturing. We also note that the variation we are detecting 
is for neutral genetic markers, those presumably not under selection, and thus do not know what changes may be occurring in loci potentially under selection such as those involved in pathogenicity.

The emergence of alternate alleles that become primary alleles shows the fluidity of genetic variation when assessed by MLVA and are a particularly important aspect of this study. Alternate alleles are traditionally ignored as noise in phylogenetic analyses. Rather than making the determination of relationships among isolates more confusing, however, alternate alleles reveal the potential mutations that connect isolates. Nonetheless, a simple depiction of the relatedness of the isolates was not possible in this study. Several of the loci were so variable that determining the direct relationship of isolates was challenging since isolates from the same animal were not always adjacent to each other on the tree. High amounts of mutations at the most variable loci and the subsequent occurrence of homoplasy reduces the utility of VNTRs for some investigations, as seen in $B$. melitensis [21] and leading to lowered weights of these types of loci in analyses [22]. If the most variable markers are excluded from analyses however, then few or no isolates are distinguishable since variation is exclusively within the most polymorphic loci. There is a fine line between adding more polymorphic loci and having that addition variation being less reliable. The application of the study is that rapid within-host evolution is occurring in Brucella infections and that we can detect it. However, this evolution is so rapid for some genetic markers that complete knowledge of the relationships of various isolates is not clear, especially for isolates collected from outbreak cases, so that fine-scale epidemiological studies are not possible in all instances.

\section{Conclusions}

The current study is the first to employ fine-scale genotyping on a comprehensive in vivo isolate collection derived from a $B$. canis outbreak. This investigation highlights the rapid genetic changes of several VNTRs of B. canis and the emergence of alternate alleles at some loci but also shows that MLVA was not an ideal method to analyse the epidemiological relationship of strains in the same outbreak. Nonetheless, the ability for B. canis to diversify over a short time frame has substantial implications for our understanding of infection caused by B. canis.

\footnotetext{
Abbreviations

VNTR: Variable number tandem repeats analysis; MLVA: Multiple locus variable number tandem repeats analysis.
}

\section{Competing interests}

The authors declare that they have no competing interests.

\section{Authors' contributions}

MG conceived of the study and with JTF wrote the manuscript and analysed the data. BDR and CAA performed the genotyping. SJ performed the bacteriological examination. PSK helped write the manuscript. All authors have read and approved the final manuscript.

\section{Acknowledgements}

MG was supported by the Lendület program (grant number: LP2012-22) of the Hungarian Academy of Sciences.

Funding from the U.S. Department of Homeland Security (DHS) supported this work. Use of product or trade names does not constitute endorsement by the U.S. Government.

\section{Author details}

'Institute for Veterinary Medical Research, Centre for Agricultural Research, Hungarian Academy of Sciences, Budapest 1143, Hungária körút 21, Hungary. ${ }^{2}$ Center for Microbial Genetics \& Genomics, Northern Arizona University, 1298 S. Knoles Drive, Flagstaff, AZ 86011-4073, USA. ${ }^{3}$ Veterinary Diagnostic Directorate, National Food Chain Safety Office, Budapest 1143, Tábornok utca 2, Hungary.

Received: 14 January 2013 Accepted: 9 April 2013

Published: 12 April 2013

\section{References}

1. Hollett RB: Canine brucellosis: Outbreaks and compliance. Theriogenology 2006, 66(3):575-587.

2. Wanke MM: Canine brucellosis. Anim Reprod Sci 2004, 82-3:195-207.

3. Lucero NE, Corazza R, Almuzara MN, Reynes E, Escobar Gl, Boeri E, Ayala SM: Human Brucella canis outbreak linked to infection in dogs. Epidemiol Infect 2010, 138(2):280-285.

4. Bricker BJ, Ewalt DR, Halling SM: Brucella 'HOOF-Prints': strain typing by multi-locus analysis of variable number tandem repeats (VNTRs). BMC Microbiol 2003, 3:15.

5. Huynh LY, Van Ert MN, Hadfield T, Probert WS, Bellaire BH, Dobson M, Burgess RJ, Weyant RS, Popovic T, Zanecki S, et al: Multiple locus variable number tandem repeat (VNTR) analysis (MLVA) of Brucella spp. identifies species-specific markers and provides insights into phylogenetic relationships. In National Institute of Allergy and Infectious Disease, NIH: Frontiers in Research. Edited by St. Georgiev V. Totowa, New Jersey: Humana Press; 2008:47-54.

6. Le Fleche P, Jacques I, Grayon M, Al Dahouk S, Bouchon P, Denoeud F, Nockler K, Neubauer H, Guilloteau LA, Vergnaud G: Evaluation and selection of tandem repeat loci for a Brucella MLVA typing assay. BMC Microbiol 2006, 6:9.

7. Whatmore AM, Shankster SJ, Perrett LL, Murphy TJ, Brew SD, Thirlwall RE, Cutler SJ, MacMillan AP: Identification and characterization of variablenumber tandem-repeat markers for typing of Brucella spp. J Clin Microbiol 2006, 44(6):1982-1993.

8. Pearson T, Okinaka RT, Foster JT, Keim P: Phylogenetic understanding of clonal populations in an era of whole genome sequencing. Infect Genet Evol 2009, 9(5):1010-1019.

9. Price EP, Hornstra HM, Limmathurotsakul D, Max TL, Sarovich DS, Vogler AJ, Dale JL, Ginther JL, Leadem B, Colman RE, et al: Within-host evolution of Burkholderia pseudomallei in four cases of acute melioidosis. PLOS Pathog 2010, 6(1):e1000725.

10. Abril C, Thomann A, Brodard I, Wu N, Ryser-Degiorgis MP, Frey J, Overesch $\mathrm{G}$ : A novel isolation method of Brucella species and molecular tracking of Brucella suis biovar 2 in domestic and wild animals. Vet Microbiol 2011, 150(3-4):405-410.

11. Bricker BJ, Ewalt DR: Evaluation of the HOOF-Print assay for typing Brucella abortus strains isolated from cattle in the United States: results with four performance criteria. BMC Microbiol 2005, 5:37.

12. Garcia-Yoldi D, Le Fleche P, De Miguel MJ, Munoz PM, Blasco JM, Cvetnic Z, Marin CM, Vergnaud G, Lopez-Goni I: Comparison of multiple-locus variable-number tandem-repeat analysis with other PCR-based methods for typing Brucella suis isolates. J Clin Microbiol 2007, 45(12):4070-4072.

13. Kang SI, Heo EJ, Cho D, Kim JW, Kim JY, Jung SC, Her M: Genetic comparison of Brucella canis isolates by the MLVA assay in South Korea. J Vet Med Sci 2011, 73(6):779-786. 
14. Al Dahouk S, Fleche PL, Nockler K, Jacques I, Grayon M, Scholz HC, Tomaso H, Vergnaud G, Neubauer H: Evaluation of Brucella MLVA typing for human brucellosis. J Microbiol Meth 2007, 69(1):137-145.

15. Kilic S, Ivanov IN, Durmaz R, Bayraktar MR, Ayaslioglu E, Uyanik MH, Aliskan H, Yasar E, Bayramoglu G, Arslanturk A, et al: Multiple-vocus variablenumber tandem-repeat analysis genotyping of human Brucella isolates from Turkey. J Clin Microbiol 2011, 49(9):3276-3283.

16. Valdezate S, Navarro A, Villalon P, Carrasco G, Saez-Nieto JA: Epidemiological and phylogenetic analysis of Spanish human Brucella melitensis strains by multiple-locus variable-number tandem-repeat typing, hypervariable octameric oligonucleotide fingerprinting, and rpoB typing. J Clin Microbiol 2010, 48(8):2734-2740.

17. Higgins J, Stuber T, Quance C, Edwards WH, Tiller RV, Linfield T, Rhyan J, Berte A, Harris B: Molecular epidemiology of Brucella abortus isolates from cattle, elk, and bison in the United States, 1998 to 2011. Appl Environ Microbiol 2012, 78(10):3674-3684.

18. Gyuranecz M, Szeredi L, Ronai Z, Denes B, Dencso L, Dan A, Palmai N, Hauser Z, Lami E, Makrai L, et al: Detection of Brucella canis-induced reproductive diseases in a kennel. J Vet Diagn Invest 2011, 23(1):143-147.

19. Foster JT, Okinaka RT, Svensson R, Shaw K, De BK, Robison RA, Probert WS, Kenefic $L$, Brown WD, Keim P: Real-time PCR assays of single-nucleotide polymorphisms defining the major Brucella clades. J Clin Microbiol 2008, 46:296-301

20. Girard JM, Wagner DM, Vogler AJ, Keys C, Allender CJ, Drickamer LC, Keim P: Differential plague-transmission dynamics determine Yersinia pestis population genetic structure on local, regional, and global scales. Proc Natl Acad Sci USA 2004, 101(22):8408.

21. Jiang H, Fan M, Chen J, Mi J, Yu R, Zhao H, Piao D, Ke C, Deng X, Tian G, et al: MLVA genotyping of Chinese human Brucella melitensis biovar 1, 2 and 3 isolates. BMC Microbiol 2011, 11:256.

22. Kattar MM, Jaafar RF, Araj GF, Le Fleche P, Matar MG, Rached RA, Khalife $S$, Gilles Vergnaud G: Evaluation of a multilocus variable-number tandemrepeat analysis scheme for typing human Brucella isolates in a region of brucellosis endemicity. J Clin Microbiol 2008, 45:3935-3940.

doi:10.1186/1746-6148-9-76

Cite this article as: Gyuranecz et al:: Within-host evolution of Brucella canis during a canine brucellosis outbreak in a kennel. BMC Veterinary Research 2013 9:76.

\section{Submit your next manuscript to BioMed Central and take full advantage of:}

- Convenient online submission

- Thorough peer review

- No space constraints or color figure charges

- Immediate publication on acceptance

- Inclusion in PubMed, CAS, Scopus and Google Scholar

- Research which is freely available for redistribution 